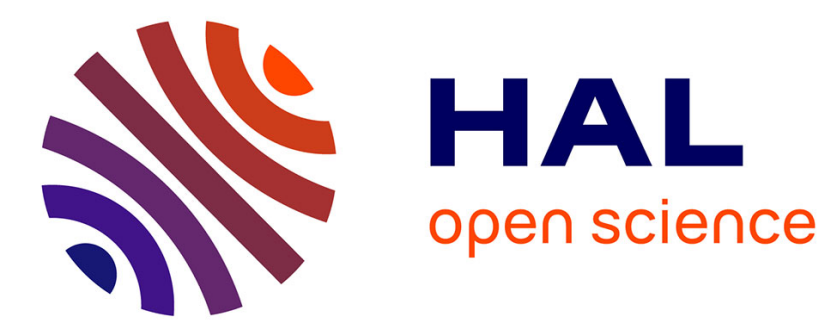

\title{
Could the Player's Engagement in a Video Game Increase His/Her Interest in Science?
}

Stéphane Natkin, Delphine Soriano, Grozdana Erjavec, Marie Durand

\section{To cite this version:}

Stéphane Natkin, Delphine Soriano, Grozdana Erjavec, Marie Durand. Could the Player's Engagement in a Video Game Increase His/Her Interest in Science?. Advances in Computer Entertainment, Nov 2013, Boekelo, Netherlands. 10.1007/978-3-319-03161-3_64 . hal-01242311

\section{HAL Id: hal-01242311 \\ https://hal.science/hal-01242311}

Submitted on 14 Dec 2015

HAL is a multi-disciplinary open access archive for the deposit and dissemination of scientific research documents, whether they are published or not. The documents may come from teaching and research institutions in France or abroad, or from public or private research centers.
L'archive ouverte pluridisciplinaire HAL, est destinée au dépôt et à la diffusion de documents scientifiques de niveau recherche, publiés ou non, émanant des établissements d'enseignement et de recherche français ou étrangers, des laboratoires publics ou privés. 


\title{
Could the player's engagement in a video game increase his/her interest in science?
}

\author{
Stéphane Natkin ${ }^{1}$, Delphine Soriano ${ }^{1}$, Grozdana Erjavec ${ }^{2}$, and Marie Durand ${ }^{2}$ \\ ${ }^{1}$ CNAM, CEDRIC, ILJ Team, Paris \\ \{stephane.natkin, delphine. soriano\} @cnam. fr \\ ${ }^{2}$ University of Paris 8, CHART Laboratory, Paris \\ grozdana.erjavec@etud.univ-paris8.fr,marie.ec.durand@gmail.com
}

\begin{abstract}
Our work is to analyze how the practice of chosen video games may influence the player's interest. A set of video games was selected by a group of experts according to their qualities as games and their relations with scientific knowledge. A focus test experiment has been set up to evaluate the correlation between teenagers engagement and their interest in scientific domains. The analysis of the results shows that the desire to pursue the game and the sentiment of responsibility has, respectively, a direct and an indirect influence on the player's scientific interest. Considering that interest is known to be an important motivational factor in learning, these results have important implications for the serious games design.
\end{abstract}

Keywords: Video games, scientific knowledge, player's engagement, serious game, focus test

\section{Introduction}

The present study is a part of the project, Recensement /INMEDIATS ${ }^{1}$, which main goals are to understand the relationship between digital entertainment and the interest in scientific knowledge. Our work is to analyze how the practice of chosen video games may influence the player's interest.

Interest is defined to be an emotional and motivational variable [1]. Furthermore, it has been established that the student's personal, situational and topic interest influence positively his/her learning outcomes [2,3]. Finally, in cognitive science, interest is considered to be very closely associated to a person's engagement in a given cognitive activity [4].

Engagement is associated with sensations such as immersion or, even more so, presence: Essentially, the sensation to "be there" [5,6,7]. In particular, Brockmyer \& al. establish the relation between engagement and emotions, as fear, in their game engagement questionnaire. Furthermore, some theoretical video game studies observed that emotion can be considered as a component of engagement $[8,9]$. On the

1 Recensement/INMEDIATS is partly funded by the Government agency ANRU with Universcience, CNAM, the University of Paris 8 as partners. 
other hand, Natkin [10] defined engagement in video games as a feeling of responsibility and Shoenau-fog [11] came to the conclusion that engagement can be conceived as a desire to pursue the game. Engaging the user in his/her experience of the product should be, among others, facilitative of cognitive efforts associated with serious aspects which might be presented in the product [12].

However, the manner in which a fun and engaging nature of an application, notably a video game, influences cognitive processes of the user has not yet been established. One way to think of such a relationship is to conceive it as being mediated by some other variable, for example the player's interest. Considering All these points of view, the present study attempts to explore the relationship between the player's engagement in a videogame and his interest in the scientific domain presented in the game.

\section{$2 \quad$ Method}

\subsection{Video games selection}

A set of video games has been selected by a group of experts. That was divided in two steps: first, from a dedicate data base, games were chosen according to their scientific aspects and gameplay qualities; Then, these shortlisted games were played by a group of scientific popularization experts and a pedagogical expert ${ }^{2}$. The final games chosen are: The Bridge (Ty Taylor and Mario Castaneda, 2013), World of Goo (2D Boy, 2008), Angry Birds Space HD (Rovio, 2012), Puddle (ENJMIN, Neko/Konami 2012) and Sim City 4 (Maxis, 2003).

\subsection{Participants}

One hundred and thirty three teenagers participated in the study, 23 girls and 110 boys. They were ranging in age from 14 to 18 years old $(M=15.360 ; S D=1.292)$, were all native speakers of French and had the habit to play video games at least three hours per week.

\subsection{Questionnaires}

For this study we designed a pre- and a post-questionnaire. The pre-questionnaire was designed to assess video games habits and school interests. It consisted of multiplechoice questions. The post-questionnaire was designed to assess the level of engagement that the video game incited in the participants, as well as participants' interest in the scientific domain that was suggest by the video game a given participant has played. The participant's engagement in the video game was assessed on three separate dimensions; the player's presence during the game, the desire to pursue playing the video game and the feeling of responsibility.

\footnotetext{
${ }^{2}$ More details on http://www.cite-sciences.fr/inmediats/seriousgame/projet.php
} 
Each section of the post-questionnaire contained several questions to which participants were asked to answer by choosing one modality on a scale going from 1 to 10 : 1 being either a highly negative answer or an answer with the lowest degree of agreement. The questions corresponding to the different sections of the postquestionnaire were conceived based on theoretical and methodological elements from previous studies $[1,2,10,11]$.

\subsection{Procedure}

The study consisted of 3 stages. In the first stage, the participant was asked to answer the pre-questionnaire. In the second stage, the participant was assigned to a video game related to a scientific domain different than his/her favorite school subject. $\mathrm{He} / \mathrm{she}$ was asked to play the game autonomously for 30 minutes. In the third and final stage the participant was invited to answer, right after they played the game, at the post-questionnaire.

\subsection{Results}

The post-questionnaire internal stability was tested with the use of Cronbach's alpha statistics ${ }^{3}$. For further analysis, only the data from sections with high reliability (Cronbach's alpha was superior to .650) were retained (Desire to pursue the game, Feeling of responsibility and Interest in scientific domain), while those from section Presence were excluded (Cronbach's alpha was inferior to .500).

In order to assess the influence of the two compound variables of player's engagement on his/her interest in the scientific domain presented in the video game he/she has played, a multiple regression analysis using a step-wise method was conducted with the Desire to pursue the game and the Feeling of Responsibility as predictor variables, and the Interest in the scientific domain as a predicted variable.

The multiple regression ${ }^{4}$ analysis results revealed a moderate to middle positive correlation among the variables $(r=.483$ for the correlation between Desire and Interest; $r=.357$ for the correlation between Responsibility and Interest; $r=.504$ for the correlation between Desire and Responsibility $)^{5}$. Furthermore, Desire, but not Responsibility, was found to have a significant contribution to predicting Interest. $(F(1,131)=39.861 ; p<.001)$ and to account for approximately 23 per cent of the variance of the predicted variable $\left(R^{2}=.233 \text {; delta } R^{2}=.227\right)^{6}$.

3 Coefficient providing a measure of the internal stability of a given questionnaire..

$4 \quad F$-test ( $F$ and $p$ values): In multiple regression, it explore whether the variables thought of as predictors have a significant effect on the predicted variable.

$5 r$ : Pearson product-moment correlation coefficient which is a measure of dependence between two variables. Its values vary between $+1-1$; the higher the absolute value of $r$, the stronger the dependence/correlation.

${ }^{6} R^{2}$ : Coefficient of determination which provides a measure of how well observed outcomes are replicated by the model. 


\subsection{Discussion and conclusion}

Roughly speaking, these results show that the Desire to pursue the game has a direct impact on the Interest in the scientific domain, while the Feeling of responsibility influences this same variable through its relation to Desire to pursue the game. Desire directly affects Interest with a very likely causal link. Similarly, Responsibility indirectly affects Interest, through Desire but this link might not be causal.

As theorized by Natkin [10], it might be linked to the Feeling of responsibility thus seems to be a component of the player's engagement. Following this research, it is necessary to validate the game questionnaire engagement on presence and to include it in our study [5]. It may help to understand better the potential relationships between the quality of a game in term of engagement and its implicit contents and messages (in our case, the scientific content) included in the same game. Finally, further research is needed in order to identify other factors influencing the player's interest for serious contents of a video game.

\section{References}

1. M. Ainley, K. Hillman \& S. Hidi. Gender and interest processes in response to literary texts: Situational and individual interest. Learning and Instruction, vol. 12, no. 4, pages 411-428, 2002.

2. K. Renninger. Individual interest and its implications for understanding intrinsic motivation. 2000.

3. U. Schiefele. Topic interest, text representation, and quality of experience. Contemporary Educational Psychology, 1996.

4. J. C. Besley \& M. C. Roberts. Qualitative interviews with journalists about deliberative public engagement. Journalism Practice, vol. 4, no. 1, pages 66-81, 2010.

5. J. H. Brockmyer, C. M. Fox, K. A. Curtiss, E. McBroom, K. M. Burkhart \& J. N. Pidruzny. The development of the Game Engagement Questionnaire: A measure of engagement in video game-playing. Journal of Experimental Social Psychology, vol. 45, pages 624-634, 2009.

6. L. Gamberini, G. Barresi, A. Maier \& F. Scarpetta. A game a day keeps the doctor away: A short review of computer games in mental healthcare. Journal of CyberTherapy and Rehabilitation, vol. 1, no. 2, pages 127-145, 2008.

7. H.T. Regenbrecht, T.W. Schubert \& F. Friedmann. Measuring the sense of presence and its relations to fear of heights in virtual environments. International Journal of HumanComputer Interaction, vol. 10, no. 3, pages 233-249, 1998.

8. A. McMahan. The Video Game, Theory Reader, 2003.

9. M. Prensky. Digital game-based learning. Comput. Entertain., vol. 1, pages 21, October 2003.

10. S. Natkin. Interactivity in Games: The Player's Engagement. IFIP Advances in Information and Communication Technology, vol. 333/2010, pages 160-168, 2010.

11. H. Schoenau-Fog. Hooked ! Evaluating Engagement as Continuation Desire in Interactive Narratives. Interactive Storytelling, pages 219-230, 2011.

12. G. Zichermann. Fun is the Future: Mastering Gamification. In http://www.gamesfornature.org/, October 2010. 